\title{
ANÁLISE JURIMÉTRICA DAS DECISÕES SOBRE A (NÃO) ABUSIVIDADE DE GREVES PELO TRIBUNAL REGIONAL DO TRABALHO DA 4 ${ }^{a}$ REGIÃO
}

\author{
Wilian Peres Chaves ${ }^{1}$ \\ Henrique Posser Martins ${ }^{2}$
}

Resumo: O presente artigo busca, através da jurimetria, analisar as decisões sobre (não) abusividade de greves no âmbito do Tribunal Regional do Trabalho da $4^{\mathrm{a}}$ Região. Faz breve resgate histórico da consolidação da greve como direito no Brasil, apresenta aspectos das construções doutrinárias em seu entorno e o tratamento jurisprudencial de seu exercício, com a análise jurimétrica das decisões e discussão sobre os seus resultados. Conclui que a Emenda Constitucional 45/2004 é um ponto de inflexão sobre os resultados das ações sobre greves e que a crença de que a Justiça do Trabalho tende a favorecer o trabalhador não se justifica.

Palavras-chave: Greve; Abusividade; Dissídio Coletivo; Jurimetria; TRT4

\section{JURIMETRIC ANALYSIS OF DECISIONS ON THE (NON) ABUSIVENESS OF STRIKES BY THE REGIONAL LABOR COURT OF THE 4TH REGION}

\begin{abstract}
This article seeks, through jurimetry, to analyze decisions on strikes and its (non) abusiveness within the scope of the Regional Labor Court of the 4th Region. It makes a brief historical review of the consolidation of the strike as a right in Brazil, presents aspects of the doctrinal constructions around it and the jurisprudential treatment of its exercise, with the jurimetrical analysis of decisions and discussion of its results. It concludes that Constitutional Amendment 45/2004 is a turning point on the results of strike lawsuits and that the belief that the Labor Court tends to favor workers is not justified.
\end{abstract}

Keywords: Strike; Abusiveness; Strike lawsuit; Jurimetry; Regional Labor Court of the 4th Region

\section{INTRODUÇÃO}

A Justiça do Trabalho brasileira é, historicamente, apontada como sendo uma instituição cujas decisões tendem a favorecer o trabalhador (YEUNG, 2017). Nos últimos anos, as frequentes modificações levadas a efeito nas leis trabalhistas tiveram como consequência a fragilização do sistema protetivo do trabalhador (MAIOR, 2018; KREIN, 2018). As difundidas crenças sobre o viés pró-trabalhador da Justiça do Trabalho integram o

1 Bacharel em Direito e mestrando em Direito pelo PPGD da Universidade Federal de Pelotas/RS (UFPel). Auditor-Fiscal do Trabalho. E-mail: wilianpc@ gmail.com. ORCID: http://orcid.org/0000-0003-3943-2241.

2 Bacharel em Direito pela Universidade Federal de Santa Maria/RS (UFSM). Mestrando em Direito pelo PPGD da Universidade Federal de Pelotas/RS (UFPel). Bolsista CAPES. E-mail: henriqueposser@gmail.com. ORCID: http://orcid.org/0000-0003-1873-5761. 
conjunto de argumentos justificadores dessas modificações. A comprovação científica de que tais crenças são infundadas é apta a prover luz de verdade sobre o assunto e embasar a luta pela reconquista destes direitos.

Partindo dessa premissa, a tarefa ora proposta consiste na análise de um tipo específico de ação, os dissídios coletivos sobre greve - e as demais formas processuais já superadas cujo objeto com eles coincidem - em um período e local específicos, conforme adiante descrito. Propõe-se então análise quantitativa apta a responder, ao menos parcialmente, a seguinte questão: as decisões de mérito sobre greves no âmbito do Tribunal Regional do Trabalho da $4^{\text {a }}$ Região (TRT4), historicamente e em termos quantitativos, podem apontar uma linha de tendência em termos de corroborar ou afastar a difundida crença de que a Justiça do Trabalho favorece o trabalhador?

O objetivo é, a partir do problema posto, verificar se é observável uma tendência, em termos de decisões, de resultados favoráveis a uma das partes, no que diz respeito a declarações da (não) abusividade de greves no âmbito do TRT4. Ao mesmo tempo, pretendese demonstrar a jurimetria como ferramenta apta a análises com abordagem voltada à verificação do impacto dos processos jurisdicionais na sociedade.

Para os fins do presente trabalho será aplicado o método da jurimetria, que consiste na análise quantitativa de decisões judiciais. Serão analisadas todas as decisões do TRT4 disponíveis em meio eletrônico que tratam da greve como matéria de mérito e de causa de decidir. As decisões serão quantificadas e analisados os argumentos e interpretações legais utilizadas nas mesmas. Os aspectos mais relevantes da consolidação quantitativa serão aprofundados buscando-se as cabíveis correlações contextuais - alterações legislativas, políticas, sociais e econômicas. Assim se quer estabelecer quais as proporções, em sede de análise meritória sobre (não) abusividade de greves, de ações procedentes e não procedentes; as respectivas correlações, sejam ligadas a alterações legislativas, temporais e outras que se mostrarem pertinentes; os argumentos utilizados como causa de decidir nos acórdãos do TRT4 nessa matéria e se há variação ao longo do tempo na interpretação dos dispositivos legais sobre greve.

Tendo em vista os objetivos do trabalho, a adoção da jurimetria para o tratamento dos dados e extração de conclusões justifica-se desde a definição de Yeung (2017), como um método de pesquisa empírico e que faz uso de instrumentos de análise estatística, aplicado ao estudo do Direito. Por sua vez, o empirismo é a prática filosófica-científica de se chegar a 
conclusões investigativas por meio da utilização de dados obtidos pela observação da realidade. Como método de pesquisa, a jurimetria não é utilizada em muitas pesquisas científicas de relevância, embora se apresente como uma abordagem com potencial de verificar problemas relativos a vários aspectos concernentes ao Direito, como a eficácia e viés das decisões judiciais (MAIA; BEZERRA, 2020).

Este artigo, além da introdução, está organizado em mais quatro seções, apresentando a evolução do tratamento legal sobre a greve no Brasil, as construções doutrinárias atuais sobre o exercício deste direito, o tratamento do direito no âmbito do TRT4 e a concomitante análise jurimétrica e, por fim, as considerações finais, consolidando as análises e apresentando conclusões.

\section{O DIREITO À GREVE}

O estabelecimento da greve como um direito, em solo brasileiro, tem sua positivação atual no texto da Constituição Federal de 1988. Esse direito é resultado de um processo histórico longo, em que é possível a identificação de diferentes fases que correspondem a diferentes tipos de abordagem e tratamento legal à greve.

Se, assim, como fato da vida a greve pouco mudou, como fato jurídico os seus contornos e consequências têm como natureza a mutabilidade. É possível identificar três vertentes de natureza jurídica da greve: como matéria criminal, como uma liberdade ou como um direito. A sua natureza varia conforme mudam as circunstâncias e o contexto político, social e econômico do local considerado, dependendo assim da maneira como o Estado, suas leis e instituições tratam o fenômeno da greve (BABOIN, 2013).

À toda evidência, como fato em si a greve pode ser identificada já nos primórdios da organização capitalista. É um fenômeno, nos limites assim postos, onipresente e com contornos de conflito. Uma manifestação coletiva cuja finalidade é a oposição ao status quo da relação de trabalho e a obtenção de uma situação melhor dentro dessa relação:

[...]todas essas vastas demandas sociais só avançaram mediante combate aguerrido, sacrifício, vertendo - continuaria a verter - muito sangue dos trabalhadores e das trabalhadoras de todos os países. Alguns exemplos mais célebres: a greve de operárias de Nova York em 8 de março de 1857, a epopéia da Comuna de Paris em 1871 e o episódio dos oito mártires de Chicago em 1896 (TRINDADE, 2002, p.144).

A legislação brasileira trata pela primeira vez da greve em 1890, através do Código 
Penal, sendo ainda durante o período de vacatio legis inserida a permissão à greve pacífica. Porém a evolução do movimento grevista e a insatisfação do setor patronal, assim como dos políticos à época, desencadeou um recrudescimento do movimento de criminalização da greve. Como conta Siqueira (2017), "a lei permitia que o governo fechasse agremiações, sindicatos ou sociedades que incitassem a prática de crimes ou atos contrários à ordem, à moralidade ou à segurança pública. Ou seja, permitia-se que o governo interviesse livremente, agora dentro da legalidade".

Durante o governo Vargas se estabelece um comportamento permissivo do estado em relação à greve que, entretanto, não é amplo, visto que segue se impondo limitações de diversas ordens ao exercício da mesma. Mesmo que pacífica, é criminalizada a greve política ou de solidariedade, ou seja, aquela que não trata das condições de trabalho ou salariais, consoante será aprofundado em item posterior.

Embora o desenvolvimento do movimento grevista brasileiro guarde relação com a chegada de europeus - em maior parte italianos - ao Brasil, que vinham inspirados pelos movimentos anarquistas e socialistas (VIANA, 2013), as primeiras greves brasileiras tinham um componente a mais, para além da luta por melhores condições de trabalho. Neste sentido, importante a menção do fato histórico da Greve Negra de 1847 na Bahia, onde negros escravos ou não - resolveram paralisar suas atividades em protesto à decisão governamental de cobrar dos trabalhadores de rua uma taxa de três mil réis, equivalente à quinze quilos de carne à época, assim como a necessidade de utilizar uma chapa de metal pendurada ao pescoço sempre que estivesse trabalhando. Foi um movimento híbrido, que auxilia a compreensão da transição da sociedade pré-industrial à industrial. Desta maneira, temos que a

[...] greve [é] uma ação em geral a favor de melhores condições de salário e trabalho. Este é o modelo europeu. Se comparado à Bahia de 1857, tivemos um movimento híbrido. Foi uma reação contra a tentativa do Estado de subtrair aos africanos "direitos e rotinas estabelecidos" (Tilly), inclusive a imposição do tal "imposto de cinco mil réis. Contra isso, não se amotinaram, fizeram greve. Os ganhadores não tinham fábrica, mas tinham cidade, eram trabalhadores informais, mas coletivamente organizados (REIS, 1993, p.29).

Assim, com a abolição da escravatura e a consolidação da formação social capitalista no Brasil, consubstanciada em um incipiente processo de industrialização, podemos destacar como episódios grevistas históricos no Brasil a greve de 1903 do movimento operário do Rio de Janeiro (ADDOR, 2007), a greve geral de julho de 1917 e a greve dos metalúrgicos do ABC paulista de 1979, entre outras (LEITE, 1987). 
Nesse contexto, a Constituição Federal de 1988 constitui um marco, na medida em que estabelece a greve como um direito, a ser exercido de forma ampla pelos trabalhadores. São bastante esclarecedoras as palavras do desembargador Jorge Luiz Souto Maior, em decisão sobre a greve dos trabalhadores do transporte coletivo de São Paulo em 2019:

A Constituição de 1988 buscou barrar um processo histórico em que o direito de greve foi, concretamente, negado em nosso país, conforme restou explícito em diversos dispositivos legais anteriores: Lei n. 38, de 4 de abril de 1935; Constituição de 1937; Decreto-Lei n. 431, de 18 de maio de 1938; Decreto-Lei n. 1.237, de 2 de maio de 1939; Código Penal de 1940; Lei n. 4.330, de $1^{\circ}$ de junho de 1964; e "Lei de Segurança Nacional", de março de 1967 (BRASIL, 2019).

A positivação constitucional foi regulamentada pela Lei 7.783/89, que estabeleceu requisitos formais e limites ao exercício do direito.

\section{CONSTRUÇÕES DOUTRINÁRIAS SOBRE O DIREITO À GREVE NO BRASIL}

A definição constitucional é a seguinte: "Art. 9. É assegurado o direito de greve, competindo aos trabalhadores decidir sobre a oportunidade de exercê-lo e sobre os interesses que devam por meio dele defender".

A Constituição deixou os limites à greve naquilo que denomina serviços e atividades essenciais e necessidades inadiáveis, no parágrafo primeiro: "§ $1^{\circ} \mathrm{A}$ lei definirá os serviços ou atividades essenciais e disporá sobre o atendimento das necessidades inadiáveis da comunidade"; e definiu que os abusos serão tratados na forma da lei, conforme o parágrafo segundo: "§2º Os abusos cometidos sujeitam os responsáveis às penas da lei".

Neste mesmo caminho o artigo 11 da lei de greve estabelece que: "Nos serviços ou atividades essenciais, os sindicatos, os empregadores e os trabalhadores ficam obrigados, de comum acordo, a garantir, durante a greve, a prestação dos serviços indispensáveis ao atendimento das necessidades inadiáveis da comunidade". E o parágrafo único do mesmo artigo esclarece: "São necessidades inadiáveis, da comunidade aquelas que, não atendidas, coloquem em perigo iminente a sobrevivência, a saúde ou a segurança da população".

É notável, conforme a literalidade dos textos constitucional e legal, a amplitude dada pelo legislador pátrio ao exercício da greve. Ela assumia então o status de direito, incluído no Capítulo II da Constituição, o mesmo em que situado o artigo $6^{\circ}$, o dos Direitos Sociais, lado a lado com os demais direitos dos trabalhadores, como o salário mínimo, as férias anuais e a 
aposentadoria. Mais ainda, o texto constitucional estabelece como titulares do direito os trabalhadores e dá a estes o poder de decidir sobre quando (a "oportunidade") e por que (os "interesses" a serem defendidos) farão greve.

Se a Constituição foi assim assertiva quanto ao direito, seus titulares e contornos, por outro lado a doutrina nacional, base e integrante das motivações de muitas sentenças e acórdãos prolatados pelo Poder Judiciário, se mostra até então bem generosa no que concerne à imposição de limites a este. Com base na formalidade do conjunto formado pela Constituição e Lei 7.783/89 temos diversas construções doutrinárias, todas visando a imposição de limites que, desrespeitados, configuram a greve como abusiva e, assim, excluída dos contornos de um direito.

Antes de introduzir os conceitos importantes para o estudo da greve, porém, insta diferenciá-lo do locaute (lockout), instrumento patronal de paralisação dos serviços a fim de pressionar possíveis insurgências operárias. Ao contrário da greve, que em democracias é protegida, o locaute é vedado, inclusive pela legislação brasileira (Lei 7.783/89, art. 17).

A fim de evitar possíveis distorções sobre o tema, repele-se a tese pela qual a proibição do locaute é uma afronta ao princípio da livre iniciativa, posto que a CRFB/88 busca valorizar os direitos sociais, a solidariedade, valorizar o trabalho humano, garantir o desenvolvimento, erradicar a pobreza, assim como estabelece um limite ao exercício da propriedade privada, ao prever a necessidade de obediência a sua função social. Portanto, sobre esse argumento:

O equívoco argumentativo mostra-se evidente. É que todos os demais princípios, fundamentos, noções e ideias incorporados, expressamente, pela Constituição, com força normativa [...], e que se colocam em contraposição frontal ao locaute, conferem, sem dúvida, atenuações e restrições aos demais valores, fundamentos, princípios e direitos assegurados pela mesma $\mathrm{CF} / 88$, relativos à livre-iniciativa e à propriedade privada (DELGADO, 2019, p.1702-1703).

Deslindada essa questão, o primeiro conceito que deve ser aclarado, neste caminho, é o de greve atípica. A ideia principal aqui é que a manifestação grevista deve ser concretizada mediante o cumprimento de diversos requisitos prévios de forma. Descumpridos estes, a manifestação é atípica e, portanto, não é uma greve, não sendo assim amparada legalmente. Uma classificação das greves atípicas que se mostra útil é a que organiza as greves atípicas a partir de cinco critérios (FERNANDES, 1990 apud BABOIN, 2013): i) quanto ao modo de 
deliberação; ii) quanto ao modo de manifestação; iii) quanto à estrutura da paralisação; iv) quanto ao modo de abstenção do trabalho; v) quanto à finalidade ou motivação.

A cada um destes critérios corresponde um requisito formal das manifestações coletivas, previsto na Lei 7.783/89 e cuja observância é necessária para a tipificação do movimento como greve. A contrário senso, a sua ausência configura uma não greve ou uma greve abusiva, não amparada pela lei.

Quanto ao modo de deliberação, temos a definição de requisito disposta no $\operatorname{artigo} 4^{\circ}$ da citada Lei de greve, que define a titularidade da assembleia geral dos trabalhadores, convocada pela entidade sindical - caso exista - na forma de seus estatutos.

A discussão cabível neste ponto é a exigência jurisprudencial e doutrinária da participação da entidade sindical. Sob a ótica dos princípios que regem o direito do trabalho, é lícito se entender que não só a inexistência, mas também a inação ou não efetividade da entidade sindical autorizaria os trabalhadores, de forma direta, a definir pela greve, já que aquela participação deve se justificar como um meio de potencializar e não limitar o exercício do direito. De qualquer forma, veremos adiante como os tribunais tratam esta questão.

Quanto ao modo de manifestação, o requisito de lei é a notificação prévia à entidade patronal ou empregadores interessados, conforme definido no parágrafo único do artigo terceiro e no artigo 13: quarenta e oito (48) horas antes da paralisação para atividades em geral, setenta e duas (72) horas para os serviços e atividades essenciais.

A estrutura de paralisação é identificável na simultânea participação - ou não - de todos os trabalhadores interessados no movimento. Em relação a este ponto, a lei não traz nenhum requisito formal ou material para tipificação de um movimento como greve. Mesmo assim, é entendimento doutrinário que as greves que não seguem este critério de uniformidade, como as greves intermitentes ou rotativas, são atípicas.

Quanto ao modo de abstenção do trabalho, a prática nos apresenta inúmeras modalidades construídas pelos trabalhadores como alternativas ao formato tradicional em que se abandona os postos de trabalho. Podemos citar a operação padrão e as greves de "braços cruzados". Em todas elas não há uma paralisação uniforme da prestação de serviços, mas ações articuladas em que o trabalho não cessa e sim tem sua produtividade, velocidade ou funcionalidade afetadas de modo significativo.

Já quanto à finalidade, a priori é constitucionalmente assegurado aos trabalhadores a liberdade de definir os interesses a serem defendidos através do movimento grevista. Em sede 
doutrinária, no entanto, este ponto remete à chamada greve política.

A greve política é uma das construções doutrinárias que giram em torno do conceito de greve abusiva ou atípica. A partir desta noção, greves legítimas são aquelas que visam defender interesses diretamente ligados ao contrato de trabalho e sobre os quais o empregador tem ingerência. Greves políticas ou de solidariedade são, ao revés, todas aquelas estranhas ao contrato de trabalho. Para Cassar (2010, p.1287), "Entende-se por greve política a dirigida contra os poderes públicos, para conseguir determinadas reivindicações não suscetíveis de negociação coletiva, tais como alteração ou criação de direitos previstos em lei". Já a greve de solidariedade é a situação onde trabalhadores aderem ao movimento paredista de terceiros, podendo ser da sua categoria ou não. Nos tribunais, inclusive o Tribunal Superior do Trabalho (TST) o tratamento da greve política é oscilante, prevalecendo de modo geral o entendimento pelo qual é abusiva (GOMES; PINTO; PINTO, 2020).

Feita a venia a este entendimento há que se afirmar que ele se coloca em clara oposição à Constituição:

[...] em momento algum, o direito de greve foi limitado quanto aos seus interesses reivindicatórios; pelo contrário, consta na Constituição e é reiterado na Lei 7.783/89 que compete aos trabalhadores decidirem "sobre os interesses que devam por meio dele defender". Este ponto, denominado causa final da greve, é o motivo central da discussão doutrinária no que concerne à legitimidade da greve política, dividindo a doutrina entre as teorias ampliativa e restritiva [...] (BABOIN, 2013).

Há entendimentos intermediários como o de Nascimento (2014) que vê limitações aos interesses a serem defendidos:

[...] as greves de política pura, que são as insurrecionais, contrariam o princípio do art. 136 da Constituição, que dispõe sobre a defesa do Estado. Não é semelhante o que ocorre com as greves de política trabalhista, como aquelas que se destinam a reivindicar a adoção de uma política salarial favorável aos assalariados (NASCIMENTO, 2014, p.1755).

Podemos ver um reflexo dessa visão mais restrita ao direito de greve na decisão do TST sobre a greve dos petroleiros de 2018 que - dentre outras reivindicações - buscava a manutenção de postos de trabalho e a não privatização da Petrobrás. Ocorre que, em decisão monocrática o Ministro Ives Gandra Filho - do Tribunal Superior do Trabalho (TST) decidiu pela abusividade da greve, em razão de sua motivação política, arbitrando sanções como corte de salários e multa entre $\mathrm{R} \$ 250.000,00$ (duzentos e cinquenta mil reais) e R\$ $500.000,00$ (quinhentos mil reais) reais por dia de descumprimento da decisão que a 
considerou abusiva.

\section{O TRATAMENTO DO DIREITO À GREVE NO ÂMBITO DO TRT4. UM EXERCÍCIO DE JURIMETRIA}

\subsection{Questões processuais}

Judicialmente, o direito à greve, ao ser exercido, está sujeito a controle exercido no âmbito da análise de alguns requisitos legais colocados pela Lei 7.783/89. Como já referido, o legislador infraconstitucional, ao regulamentar o direito à greve, colocou como condições diversas condutas que devem ser previamente observadas, antes da efetiva deflagração do movimento grevista.

Durante a análise dos acórdãos, constatou-se que, em termos de formatação processual, a apreciação da (não) abusividade de uma greve tomou formas distintas dentro do período considerado.

Entre 1994 e 2004, os pedidos contendo essa pretensão eram veiculados sob forma de uma petição endereçada ao Tribunal contendo um pedido de declaração da abusividade da greve, de titularidade da entidade patronal ou da empresa cujos trabalhadores deflagraram o movimento. A partir de 2009, a análise sobre o mérito de abusividade das greves tinha como premissa a instauração de um dissídio coletivo de greve, cuja titularidade se atribui, além dos já citados, também aos sindicatos de trabalhadores e, quando se tratar de greve em atividade essencial, ao Ministério Público do Trabalho.

Temos então que

Em sua natureza jurídica mista, a um só tempo declaratória e condenatória, o dissídio coletivo de greve tem por finalidade imediata a obtenção de pronunciamento jurisdicional sobre a legalidade ou a ilegalidade de uma greve, mas também comporta a previsão de condições de trabalho a serem observadas na retomada da prestação dos serviços, tais como o eventual pagamento dos dias de paralisação (BRASIL, 2009).

Por outro lado, algumas decisões envolvendo análise de legitimidade de greve não o fazem em caráter e com efeitos coletivos - erga omnes - mas sim de forma incidental e inter partes:

A competência para o exame de legalidade e legitimidade de movimento paredista, trazido a juízo como questão incidental e prejudicial ao efetivo direito postulado pagamento dos salários dos dias de paralisação -, é do primeiro grau de jurisdição, 
que não pode deixar de apreciar a demanda, sob pena de afronta aos arts. $5^{\circ}, \mathrm{XXXV}$, e 9 ${ }^{\circ}$, ambos da CF. (Acórdão: 0101600-39.2003.5.04.0611 (RO) Redator: MILTON VARELA DUTRA Participam: Maria Beatriz Condessa Ferreira, João Pedro Silvestrin Órgão julgador: 4a. Turma Data: 14/07/2005).

Acórdão este que deve ser contextualizado com a orientação jurisprudencial 12 da SDC do TST, verbis: “GREVE. QUALIFICAÇÃO JURÍDICA. ILEGITIMIDADE ATIVA "AD CAUSAM"DO SINDICATO PROFISSIONAL QUE DEFLAGRA O MOVIMENTO.

Não se legitima o Sindicato profissional a requerer judicialmente a qualificação legal de movimento paredista que ele próprio fomentou".

Conclui-se então, que demandas de trabalhadores, individualmente ou em conjunto que tenham como substrato principal ou acessório a análise de legitimidade de um movimento grevista tem como competente para dita análise o juízo de $1^{\circ}$ grau. Tais questões ascendem ao Tribunal em sede de Recursos Ordinários, que incidentalmente e apenas para os fins daquela ação específica analisam a legitimidade da greve.

Para fins da análise jurimétrica, foram utilizados os acórdãos disponíveis na pesquisa de jurisprudência do sítio do Tribunal Regional do Trabalho da $4^{\mathrm{a}}$ Região (TRT4). A pesquisa por acórdãos contendo a palavra "greve" na ementa retornou 269 resultados. Como o objetivo é verificar em termos quantitativos as decisões que tratam de (não) abusividade de greves, foram excluídos os resultados em que aquele termo remetia a questões envolvendo terceiros, como trabalhadores afetados por uma greve nos transportes, por exemplo. Também foram excluídos processos que tratam de questões individuais envolvendo greves já declaradas abusivas em processo próprio, pelos mesmos motivos. A decisão mais antiga disponível em meio eletrônico data de 1994, o que resulta em um interregno de 26 (vinte e seis) anos de ações sob investigação.

\subsection{Distribuição cronológica}

Como já referido, o lapso temporal analisado corresponde a 26 (vinte e seis) anos de atividade do TRT4. Visualmente, a distribuição temporal dos acórdãos é a da Figura 1. 


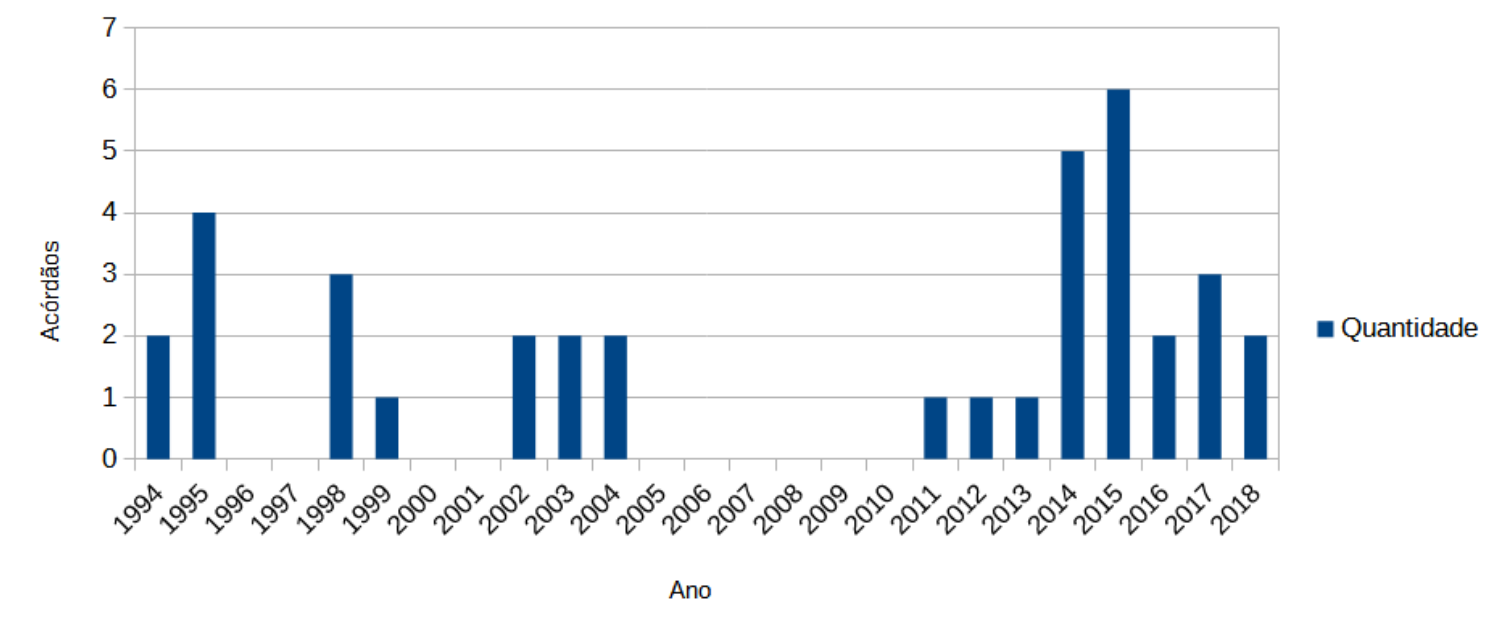

Figura 1 - Distribuição cronológica dos acórdãos

Evidencia-se no gráfico um grande hiato, entre 2005 e 2010, em que absolutamente não estão disponíveis acórdãos decidindo sobre a abusividade de nenhuma greve. Se decerto houve greves neste período, a questão que surge é por que nenhuma delas foi analisada pelo Poder Judiciário.

A questão envolve vários aspectos que serão agora apresentados. O primeiro - e talvez o maior - fato relevante é a aprovação da Emenda Constitucional 45/2005, que alterou o $\S 2^{\circ}$ do art. 114 nos seguintes termos:

Art. 114. Compete à Justiça do Trabalho processar e julgar:

[...]

$\S 2^{\circ}$ Recusando-se qualquer das partes à negociação coletiva ou à arbitragem, é facultado às mesmas, de comum acordo, ajuizar dissídio coletivo de natureza econômica, podendo a Justiça do Trabalho decidir o conflito, respeitadas as disposições mínimas legais de proteção ao trabalho, bem como as convencionadas anteriormente.

A redação anterior era a seguinte:

$\S 2^{\circ}$ Recusando-se qualquer das partes à negociação ou à arbitragem, é facultado aos respectivos sindicatos ajuizar dissídio coletivo, podendo a Justiça do Trabalho estabelecer normas e condições, respeitadas as disposições convencionais e legais mínimas de proteção ao trabalho.

O ponto nevrálgico aqui é a inserção da expressão "de comum acordo". Imediatamente a isso, alguns Tribunais passaram, em sede de dissídio coletivo, a aplicar o dispositivo literalmente. No caso do TRT4, esse foi o entendimento inicialmente adotado: "A concordância dos sindicatos suscitados é pressuposto de constituição e desenvolvimento válido e regular dos dissídios coletivos ajuizados a partir de $1^{\circ}$ de janeiro de 2005". A análise 
dos acórdãos revela, no entanto, que rapidamente o entendimento adotado foi no sentido de considerar a expressão facultativa, nos seguintes termos:

\begin{abstract}
A exegese que se faz do novo texto constitucional é no sentido de que o poder constituinte derivado consagrou mera faculdade ao tratar do consenso das partes na proposição da ação coletiva de natureza econômica, na medida em que a frustração da negociação prévia permanece como pressuposto do ajuizamento do dissídio coletivo, não havendo, por isso, que se falar em inconstitucionalidade da expressão "de comum acordo". Na hipótese em que é buscada a conciliação entre as partes (negociação prévia), mas esta não é alcançada, é possível o ajuizamento do dissídio coletivo de natureza econômica por quaisquer das entidades sindicais, sob pena de se eliminar o direito constitucional de ação previsto como norma pétrea no inciso XXXV do art. $5^{\circ}$ da Constituição Federal.
\end{abstract}

O entendimento inicial, no entanto, certamente teve efeitos anímicos importantes, como demonstra a propositura de cinco ADIs, cujos resultados, exarados em maio de 2020, concluíram pela constitucionalidade do dispositivo ora abordado.

Para além desse aspecto, a mesma Emenda inseriu no art. 114 o $\S 3^{\circ}$ : "Em caso de greve em atividade essencial, com possibilidade de lesão do interesse público, o Ministério Público do Trabalho poderá ajuizar dissídio coletivo, competindo à Justiça do Trabalho decidir o conflito". Consolida-se a presença de um novo legitimado à propositura de dissídios coletivos, o que teoricamente tende a aumentar o número de ações desse tipo. Não só isso, a drástica ampliação da competência material da justiça do trabalho, ao trazer um maior número de demandas a esse órgão do Judiciário, certamente diminui sua agilidade de resposta, o que explicaria a maior quantidade de autocomposições e traduziria os números apresentados.

Outro fato, chamado à atenção por Mandl (2014), antecede o cancelamento da Orientação Jurisprudencial nº 01 da Seção de Dissídios Coletivos, que declarava abusiva as greves deflagradas contra o descumprimento de acordos e convenções:

[...] a partir de 2003, com a mudança do Presidente do TST, inicia-se algumas mudanças no raciocínio dos magistrados, reforçando a necessidade dos requisitos formais para interpor dissídios coletivos, mas ao invés de imediatamente definir a greve como abusiva, aumentaram-se casos onde o desfecho foi ter justamente impedimentos formais, extinguindo muitas vezes as ações "sem julgamento do mérito", ou mesmo, suspendendo por vezes os dissídios, negociando compensação de horas, chamando as partes para conciliações, entre outras medidas que mostraram uma nova tentativa do TST enfrentar os conflitos grevistas.

Como fato então, conforme a abordagem do presente trabalho, a Emenda Constitucional 45/2004, ao mesmo tempo em que ampliou a competência material da justiça do trabalho, teve como uma de suas consequências a diminuição a zero, por um período de 
seis anos, do número de acórdãos contendo análise da legitimidade de greves, no âmbito do TRT4.

\subsection{Análise do mérito}

Das decisões que analisam a (não) abusividade da greve, 52 (cinquenta e duas) o fazem tendo essa análise como mérito da ação. Esse conjunto contém três classes de ação: i) dissídios coletivos de greve; ii) dissídios coletivos; e iii) Ações declaratórias de abusividade/ ilegalidade de greve. Todas elas de competência originária dos Tribunais e cujo objeto é exatamente a declaração da (não) abusividade do movimento. No caso específico dos dissídios coletivos, como já referido, o objeto é o julgamento de cláusulas de convenções coletivas e decisões de mérito sobre as greves são raras.

Dessas 52 (cinquenta e duas), um total de 15 (quinze) ações tiveram decisões sem análise do mérito, pela ocorrência de um acordo, desistência no âmbito do processo, ou por declaração de ilegitimidade ativa ou passiva de alguma das partes, restando 37 (trinta e sete) decisões de mérito.

Outras 12 (doze) ações, embora se tratando de Recursos Ordinários em matéria trabalhista, cuja competência é das Varas do Trabalho, de $1^{a}$ instância, contém declarações de (não) abusividade de greve, cuja apreciação não foi feita em sede de dissídio coletivo, mas se mostrou necessária como matéria prévia à apreciação do mérito próprio da ação; ou seja, em que a (não) abusividade consta questão prejudicial à análise do mérito.

Temos então, adotando como critério de divisão a análise da greve no mérito da ação ou questão prejudicial, um total de 49 (quarenta e nove) decisões. Outras (15) quinze decisões foram de extinção da ação sem resolução do mérito pela ocorrência de acordo entre as partes.

Uma visualização geral dos quantitativos descritos pode ser conferida na Tabela 1.

\begin{tabular}{l|l} 
Decisões de mérito em sede de dissídio coletivo / petição & 37
\end{tabular}

\begin{tabular}{l|l} 
Decisões de mérito em sede de recurso ordinário & 12
\end{tabular}

Decisões sem resolução de mérito em dissídio coletivo/ petição 15

\begin{tabular}{l|l} 
Total de decisões em DC/PET & 52
\end{tabular}

\begin{tabular}{l|l} 
Total de decisões de mérito & 49
\end{tabular} 


\section{Total geral}

\section{4}

Tabela 1 - Quantitativo de decisões sob análise

\subsection{Procedência da ação}

Em relação à procedência da ação, temos um total de 52 (cinquenta e dois) acórdãos, sendo então destes 22 (vinte e dois) de procedência, 15 (quinze) de não procedência e 15 (quinze) sem resolução de mérito. Em termos proporcionais, teríamos 56,67 \% de acórdãos procedentes, $13,33 \%$ de não procedentes e $30 \%$ em que não há resolução de mérito.

Se excluirmos deste microuniverso os acórdãos de extinção do processo sem resolução do mérito, resta um total de 37 (trinta e sete) decisões com resolução de mérito em sede de dissídio coletivo ou ação declaratória de abusividade. Para efeitos de consolidação da análise quantitativa, as decisões que declaram a greve como abusiva serão chamadas de "sentenças de procedência", já que em sede de dissídio coletivo o pedido é formulado pela entidade patronal, empresa ou MPT, buscando a condenação de uma entidade sindical de representação dos trabalhadores e a declaração de abusividade da greve. Os acórdãos referentes a recursos ordinários com análise incidental de abusividade serão abordados em item próprio, já que representam demandas individuais.

Em termos quantitativos proporcionais, para as sentenças com resolução de mérito em sede de dissídio coletivo o índice de procedência é de 59,46 \%. Restam, portanto, 40,54\% de ações não procedentes.

Essas proporções se alteram profundamente se fizermos um corte temporal. Ao dividirmos estes acórdãos em dois grupos, o primeiro contendo as decisões exaradas entre 1994 e 2004 e o segundo aquelas entre 2011 e 2018 (estabelecendo como corte aquele hiato entre decisões que coincide com a publicação da Emenda Constitucional nº5/2004, já referido), os quantitativos são reveladores.

Para o primeiro grupo, de um total de 16 (dezesseis) decisões, 5 (cinco) são de procedência e 11 (onze) declarando a greve não abusiva. Temos então 31,25\% de acórdãos procedentes versus $68,75 \%$ de acórdãos de não procedência. Indo além, das cinco declarações de abusividade deste grupo, quatro (80\%) se deram em dois anos, 1994 e 1995. Já no segundo grupo, de 21 (vinte e uma) decisões, 17 (dezessete), ou 80,95\% foram a favor da abusividade da greve e 4 (quatro), ou 19,05\% em contrário. Ou seja, em termos de resultado é visível uma 
absoluta inversão de tendência, consolidada após a Emenda Constitucional 45/2004, o que pode ser melhor visualizado na Figura 2.

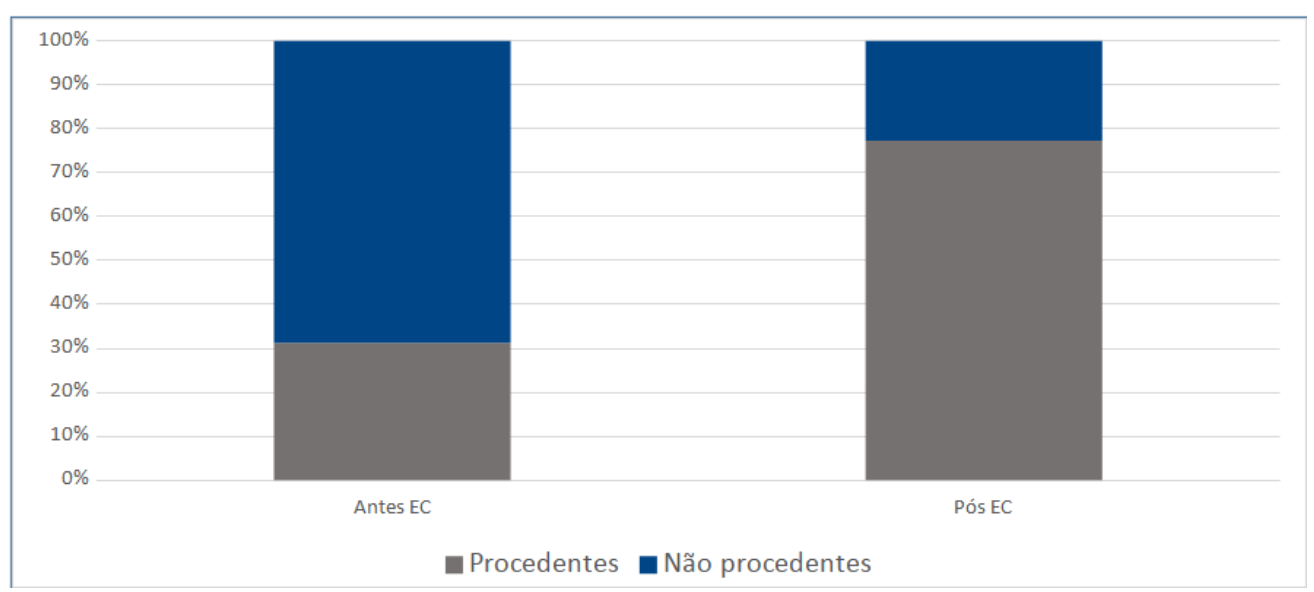

Figura 2 - Distribuição percentual geral dos acórdãos em termos de procedência - Antes e após a EC 45

Sob outro viés, é possível observar que 77,27\% de todas as declarações de abusividade nos processos disponíveis para consulta no sítio do TRT4 foram exarados após 2009.

\subsection{Atividade essencial}

Em relação à atividade dos trabalhadores grevistas, dos 37 (trinta e sete) processos cujo mérito foi analisado em 26 (vinte e seis) a atividade era essencial, nos termos do art. 10 da Lei 7.783/89, o que fecha um percentual de 70,27\%. Dentro desse grupo o percentual de procedência é de 65,38\%, o que em números absolutos corresponde a 17 (dezessete) acórdãos de 26 (vinte e seis) possíveis.

Se procedermos novamente ao recorte temporal acima realizado, entre 2011 e 2019 o percentual de procedência das ações quando a atividade é essencial é de $88,24 \%$ ou 15 (quinze) entre 17 (dezessete). Já no primeiro grupo (1994-2004), esse percentual é de 22,22\%, ou 2(dois) de 9 (nove) acórdãos. A inversão de tendência acima constatada reproduz-se, portanto, no caso dos serviços essenciais ainda com mais força.

Novamente o recorte temporal, coincidente com a publicação da Emenda Constitucional 45/2004, representa um ponto de inflexão quanto ao resultado das demandas. Em termos de número de ações propostas, é certo que houve um aumento proporcional, 
certamente fruto do aumento de escopo e da inclusão do MPT como legitimado. Quanto aos índices de procedência, no entanto, as razões devem ser aprofundadas e, para tanto, se procedeu à análise dos fundamentos utilizados nos acórdãos, consolidada no item seguinte.

\subsection{Fundamentos legais e jurídicos}

Entre as 37 (trinta e sete) ações pugnando a abusividade do movimento grevista como mérito, a distribuição dos argumentos jurídicos utilizados como fundamento apresenta os números abaixo apresentados. Importante ressaltar que os argumentos analisados na análise não são excludentes entre si, ou seja, os acórdãos podem ter utilizado um ou mais deles.

Dos 22 (vinte e dois) acórdãos de procedência, declarando a greve abusiva, 15 (quinze) ou 68,18\% se fundam no não atendimento das necessidades dos usuários; 6 (seis) ou $27,27 \%$ na ausência da comunicação prévia de 72 horas (atividade essencial, art.13 da L7783/89).

Já entre os 15 (quinze) acórdãos não procedentes, o argumento mais recorrente foi o da existência de atraso de salários, a justificar o não cumprimento dos requisitos formais dos arts. $3^{\circ}$, p. único e $4^{\circ}$ da L7783/89. Esse argumento esteve presente em 5 (cinco), ou 33,33\% das decisões. Neste grupo, os argumentos que convém destacar se referem a conceitos cuja instrumentação se mostrou peculiar.

Em um dos acórdãos (0839800-35.2001.5.04.0000) ${ }^{3}$ restou declarado, com resolução de mérito, se tratar de movimento com cunho político, à qual não se aplicaria a Lei de Greve. Não se partiu à extinção do processo. Já no processo 0563300-48.1997.5.04.0000, a decisão foi no sentido da improcedência da ação, por não haver prova da participação do sindicato e se tratar de movimento espontâneo, deflagrado por pequena parcela de empregados da empresa (motoristas). Ora, nos dois casos tratou-se, a rigor e conforme a conduta recorrente dos Tribunais, de descumprimento de requisitos legais e, portanto, de abusividade. No entanto, em ambas a conclusão foi pela não existência de greve e, portanto, de não abusividade de algo que não ocorreu.

O recorte temporal já estabelecido torna mais evidentes algumas relações. Para o grupo anterior à EC 45/2004, de 16 (dezesseis) decisões tivemos 11 (onze) de improcedência,

3 Todos os processos citados pelo número podiam ser consultados no sítio do TRT4: https://www.trt4.jus.br/portais/trt4/acordaos, até a data de 27 set. 2020. 
dentre as quais 5 (cinco) utilizaram o argumento da mora salarial. Em outras palavras, de todos os acórdãos utilizando este argumento, todos o fizeram antes da EC45.

\subsection{Declarações incidentais de (não) abusividade}

Como já referido, foram identificadas 12 (doze) declarações incidentais de (não) abusividade da greve, em ações que ascenderam ao tribunal via recurso ordinário. Aqui a greve consiste em questão prejudicial ao mérito. Todas ocorreram após a EC 45/2004 Em relação à procedência, 4 (quatro) decisões consideraram a greve como ilegal ou abusiva. Destas, duas tiveram como fundamento a essencialidade do serviço e a não obediência de formalidades da lei. Uma delas se referiu a turbação de posse e uma ao caráter político do movimento.

Das 8 (oito) decisões que consideraram o movimento legítimo, metade delas fez constar explicitamente que não há vedação a greves políticas ou de solidariedade no direito brasileiro, sendo que três delas referiam-se a movimentos em oposição à reforma trabalhista de 2017. As outras 4 (quatro) se referiram ao cumprimento dos aspectos formais.

Em termos de análise, nota-se que, em sede de declarações incidentais, a tendência é inversa àquela observada para o grupo de acórdãos em sede de ações coletivas pós EC45/2004. Aqui o índice de declarações pró-trabalhador supera em dois para um as declarações de abusividade.

É fato, portanto, que em sede de decisões com efeitos individuais o tribunal tende a tratar com menos rigor a análise da legitimidade da greve. Uma possível explicação é o efeito da opinião pública, visto que as decisões em caráter coletivo nos dissídios de greve, mormente quando se referem a serviços essenciais, tendem a ocupar o noticiário e atrair a atenção popular, normalmente imperando uma visão negativa do movimento (MANDL, 2014, p.72). A liberdade para decidir, portanto, sofre a influência respectiva.

\subsection{Extinção sem análise do mérito}

Das 15 (quinze) decisões encerrando o processo sem análise de mérito, 10 (dez) ocorreram após entrada em vigor da EC45. Destas dez, 9 (nove) tiveram como causa da extinção a ocorrência de um acordo que prejudicou a análise do mérito da legalidade da greve. 
O acordo é causa de extinção em apenas outras 3 (três) ações em todo o período anterior. É possível visualizar o raciocínio de Mandl (2014), aqui já exposto, que observa a partir de 2005 a tendência a interpretar de forma mais rigorosa a questão da análise de requisitos formais e dar preferência às negociações.

Ponto notável é o processo 0020959-68.2014.5.04.0000, cuja extinção se deu pelo movimento não ter sido considerado greve, tendo sido isso assentado como falta de condição da ação. Trata-se de entendimento contrário ao exarado no processo 056330048.1997.5.04.0000, no qual, como já citado, entendeu-se pela improcedência da ação.

\section{CONSIDERAÇÕES FINAIS}

A análise, dentro do escopo considerado, proporcionou resultados relevantes. A Emenda Constitucional 45/2004 pode ser considerada um ponto de ruptura ou inflexão no que concerne ao resultado de mérito (procedência) dos dissídios coletivos de greve. A interpretação e uso de certos conceitos, como a relativização de formalidades em virtude do atraso de salários também tem um corte marcado pelo mesmo fato (EC 45), além de apresentarem uma variabilidade em sua instrumentação, nem sempre condizente com a doutrina e a interpretação dos tribunais superiores, como se pôde verificar nas questões da greve política e das não-greves (atípicas em sentido estrito).

Indo mais além, mostra-se, dentro do universo específico deste estudo, infundada a afirmação de que a Justiça do Trabalho tenda a exarar decisões em prol dos trabalhadores, pelo menos a partir da já referida emenda.

O estudo em si permitiu constatar que a disponibilidade de dados nem sempre é total e apta a produzir resultados relevantes, sendo necessária sua ampliação e a abordagem de outros aspectos. Mais importante, demonstra o grande potencial do uso da jurimetria. A extensão da base de dados sob análise, abrangendo outros tribunais e abordando outros aspectos dos resultados, como os de ideologia, gênero dos julgadores, contexto político e de opinião pública, por exemplo, pode resultar em conclusões mais abrangentes e generalizáveis. Desta forma, a ampliação da abordagem para outras classes de ações ou mesmo a inclusão de dados de outros tribunais são caminhos que permitem a ampliação da força das análises aqui postas. 


\section{REFERÊNCIAS BIBLIOGRÁFICAS}

ADDOR, C. A. A greve de 1903: primórdios do movimento operário no Rio de Janeiro. História, Ciências, Saúde-Manguinhos, v. 14, n. 2, p. 635-639, jun. 2007. ISSN 0104-5970. Editor: Casa de Oswaldo Cruz. Disponível em: $<$ http://www.scielo.br/scielo.php?script=sci_abstract\&pid=S010459702007000200017\&lng=en\&nrm=iso\&tlng=pt>. Acesso em: 25 Set. 2020.

BABOIN, J. C. d. C. O tratamento jurisprudencial da greve política no Brasil. Tese (Doutorado) - Universidade de São Paulo, maio 2013. Disponível em: <http://www.teses.usp.br/teses/disponiveis/2/2138/tde-10012014-153923/>. Acesso em: 05 Set. 2020.

BRASIL. TRIBUNAL SUPERIOR DO TRABALHO. Processo: RODC 2019200-36.2007.5.02.0000. Relator: Walmir Oliveira da Costa, Seção Especializada em Dissídios Coletivos. Jusbrasil, São Paulo, SP, Fev.2009. Disponível em: <https://tst.jusbrasil.com.br/jurisprudencia/2353419/recurso-ordinario-em-dissidio-coletivorodc-2019200362007502-2019200-3620075020000>. Acesso em: 25 Set. 2020.

BRASIL. TRIBUNAL REGIONAL DO TRABALHO DA 15ª REGIÃO. Processo: 000694160.2019.5.15.0000 TutCautAnt. Relator: Jorge Luiz Souto Maior, Seção de Dissídios Coletivos. Jusbrasil, São Paulo, SP, Dez. 2019. Disponível em: <https://trt15.jusbrasil.com.br/jurisprudencia/795800778/tutcautant-69416020195150000-00069416020195150000/inteiro-teor-795800981>. Acesso em: 07 Jul. 2020.

CASSAR, V. B. Direito do trabalho. 4. ed. Niterói: Editora Impetus, 2010.

DELGADO, M. G. Curso de direito do trabalho. 18. ed. São Paulo: Editora LTr, 2019.

FERNANDES, A. M. Greves "atípicas": identificação, caracteres, efeitos jurídicos. AAVV., Temas de direito do trabalho, p. 491-518, 1990.

GOMES, A. V. M.; PINTO, F. A. C. F.; PINTO, C. E. F. O direito de greve como manifestação do exercício da democracia: Análise da decisão do TST sobre a legitimidade da greve política. Revista Chilena de Derecho del Trabajo y de la Seguridad Social, v. 11, n. 21, p. 47-64, jun. 2020. ISSN 0719-7551. Number: 21. Disponível em: <https://ultimadecada.uchile.cl/index.php/RDTSS/article/view/57844>. Acesso em: 26 Set. 2020 .

KREIN, J. D. O desmonte dos direitos, as novas configurações do trabalho e o esvaziamento da ação coletiva: consequências da reforma trabalhista. Tempo social, v. 30, n. 1, p. 77-104, 2018. Acesso em: 04 Set. 2020.

LEITE, M. d. P. O movimento grevista no Brasil. São Paulo: Editora Brasiliense, 1987. (Tudo é história, 120). Disponível em: <http://www.cedec.org.br/files_pdf/OmovimentogrevistanoBrasil.pdf>. Acesso em: 25 Set. 2020. 
MAIA, M.; BEZERRA, C. A. Análise bibliométrica dos artigos científicos de jurimetria publicados no Brasil. RDBCI: Revista Digital de Biblioteconomia e Ciência da Informação, v. 18, p. e020018-e020018, jun. 2020. ISSN 1678-765X. Disponível em: <https://periodicos.sbu.unicamp.br/ojs/index.php/rdbci/article/view/8658889>. Acesso em: 27 Set. 2020.

MAIOR, J. L. S. A "reforma" trabalhista e seus reflexos no direito coletivo do trabalho. Direito UNIFACS-Debate Virtual, n. 211, 2018.

MANDL, A. T. A judicialização dos conflitos coletivos de trabalho : uma análise das greves julgadas pelo TST nos anos 2000. Dissertação (Mestrado), 2014. Disponível em: <http://repositorio.unicamp.br/jspui/handle/REPOSIP/286443>. Acesso em: 26 Set. 2020.

NASCIMENTO, A. M. Curso de Direito do Trabalho: história e teoria geral do direito do trabalho: relações individuais e coletivas do trabalho. 29. ed. São Paulo: Saraiva, 2014.

REIS, J. J. A greve negra de 1857 na Bahia. Revista USP, n. 18, p. 6-29, 1993.

SIQUEIRA, G. S. História do direito de greve no Brasil (1890-1946): criminalização, mito da outorga e movimentos sociais. Rio de Janeiro: Lumen Juris, 2017. (Coleção Direito e Emancipação, 3).

TRINDADE, J. D. d. L. História social dos direitos humanos. São Paulo: Editora Peirópolis, 2002.

VIANA, M. T. 70 anos de CLT: uma história de trabalhadores. Tribunal Superior do Trabalho, 2013.

YEUNG, L. Jurimetria ou análise quantitativa de decisões judiciais. In: Pesquisar empiricamente o Direito. São Paulo: Rede de estudos empíricos em direito, 2017. p. 249 274.

274. 